\title{
As moedas romanas e os estudos numismáticos contemporâneos
}

\author{
Roman coinage and contemporary numismatic studies
}

KEMMERS, F. The functions and use of Roman coinage: an overview of $21^{\text {st }}$ century scholarship. Leiden: Brill, 2019. 89 p.

\section{João Carlos Furlani`}

Recebido em: 10/06/2020

Aprovado em: 30/06/2020

U

ma moeda é, por definição, uma peça fabricada em material resistente, na maioria das vezes metal, em formato circular, imbuída de valor e utilizada como dinheiro. Tradicionalmente, as moedas possuíam valor equivalente ao do metal com o qual eram confeccionadas, mas, hoje, a produção de uma moeda costuma ser mais onerosa que o valor que ela representa no mercado. Por esse motivo, podemos compreender as moedas contemporâneas regulares como um item de valor econômico reduzido se comparado às cédulas impressas, aos cheques, aos cartões de crédito e aos inúmeros outros meios virtuais de capitalização do dinheiro. As imagens contidas nos objetos monetários da atualidade já não são tão mutáveis e associadas aos governos vigentes como outrora, nem mesmo aquelas confeccionadas em datas comemorativas.

As moedas romanas, por outro lado, demonstravam uma diversificação muito grande em um curto espaço de tempo. Suas imagens apresentavam propósitos simbólicos e divulgavam mensagens altamente inteligíveis ao maior número de habitantes possível. Em consonância ou não com os textos e demais elementos da cultura material, as moedas transmitiam uma imagem específica que nem sempre poderia ser alcançada por meio das fontes textuais. Em outras palavras, o texto cultural monetário era transmissor de um discurso rico e dotado de intenções sociopolíticas, religiosas e culturais. Por meio da catalogação e análise é possível enxergar significados intrínsecos às moedas

\footnotetext{
* Doutorando em História pelo Programa de Pós-Graduação em História (PPGHis) da Universidade Federal do Espírito Santo (Ufes), sob orientação do prof. Dr. Gilvan Ventura da Silva. Mestre, licenciado e bacharel em História pela mesma instituição. Faz parte do Laboratório de Estudos sobre o Império Romano, seção ES (Leir/ES).
} 
romanas que vão além do sistema econômico, uma vez que tais artefatos eram também portadores e difusores de crenças, memórias, comemorações e representações daqueles homenageados em seu anverso e/ou reverso (FRÈRE, 1984, p. 15).

Entre as várias características das moedas, algo que costuma despertar o fascínio e a curiosidade tanto de especialistas quanto de colecionadores, destaca-se a significativa presença de imagens e inscrições cunhadas nos anversos e reversos desses objetos. Deuses, soberanos, locais religiosos, templos, altares, monumentos, práticas religiosas, sacrifícios e cerimônias não são representações estranhas aos estudiosos da numismática e muito menos aos indivíduos que manipulavam esses valiosos pedaços de metal na Antiguidade (WILLIAMS, 2007, p. 144). A moeda romana é, sem dúvida, um artefato peculiar e interessante. Não à toa, diversos exemplares descobertos foram catalogados e disponibilizados em bancos de dados disponíveis a nós hoje, sobretudo por numismatas.

Indubitavelmente, a Numismática nos permite perceber uma série de elementos presentes na sociedade romana. Mas, apesar da reconhecida importância das moedas como fontes de informação para o Mundo Antigo, para as empregarmos da maneira devida é imprescindível que façamos alguns questionamentos, tais como: o que define uma moeda romana? Qual o seu significado e para que e quem era cunhada? Qual o impacto dela na sociedade que as manipulava? E, afinal, como estudar essas moedas? Todas essas indagações, por mais que já tenham sido diversas vezes respondidas, não são um axioma, uma vez que continuam a sofrer impacto tanto das transformações acadêmicas quanto do mundo do qual fazem parte. É com vistas a essa problemática que Fleur Kemmers, professor da Universidade Goethe, em Frankfurt, Alemanha, dedicou esforços para elaborar The functions and use of Roman coinage: an overview of $21^{\text {st }}$ century scholarship, obra publicada originalmente em 27 de junho de 2019, como parte da coleção Brill Research Perspectives da editora Brill.

Na abertura de seu livro, Kemmers evoca as considerações realizadas por Arnold Hugh Martin Jones (1956) em Numismatics and History, capítulo no qual o autor parabeniza os numismáticos por seu trabalho meticuloso de catalogação de moedas antigas, mas, ao mesmo tempo, os critica por terem se desviado em demasia da produção de conhecimento feita pela História Antiga. Jones (1956, p. 32) também deixa transparecer o valor que ele acreditava que a Numismática possuía: o de fornecer dados para os historiadores construírem suas análises. Opinião essa amplamente difundida no campo da História, a qual por longo tempo encarou outras disciplinas como meras auxiliares na produção do saber científico. A partir desse pressuposto, Kemmers (2019, p. 2) indaga: o que mudou desde então? A Numismática ainda é percebida fundamentalmente como uma serva 
da História? Os próprios numismatas veem sua função primordial como a de produzir catálogos? Eles consideram o estudo das moedas uma "ciência por si só"?

$\mathrm{Na}$ empreitada para responder a essas perguntas, Kemmers precisou mergulhar na recente historiografia do final do século XX e do início do século $X X I$, definir conceitos e apresentar as abordagens mais tradicionais da área. De maneira geral, a obra resenhada pode ser dividida em diferentes momentos. Em primeiro lugar, temos uma seção introdutória, voltada para o estudo da Numismática como disciplina e as mudanças conceituais, teóricas e metodológicas ocorridas em seu âmbito nas últimas décadas. Em seguida, e de maneira mais didática, Kemmers fornece diretrizes sobre como consultar trabalhos de referência numismáticos, o que inclui acervos e bancos de dados online, além da própria compreensão dos usos dos objetos monetários para distintas finalidades. Ao longo de sua explanação, o autor também tece críticas e discute abordagens recorrentes no campo da Numismática romana, mas sempre com uma linguagem simples e clara, lembrando que seu público-alvo são estudantes e acadêmicos dedicados ao estudo da História Antiga e da Arqueologia Clássica

Mais especificamente, The functions and use of Roman coinage encontra-se dividida em sete partes, sendo cinco capítulos de conteúdo propriamente dito, precedidos de um capítulo introdutório e seguidos das considerações finais. Em sua introdução, Kemmers (2019, p. 1-5) esclarece de forma prática pontos fundamentais para a compreensão das moedas como um tipo especial de fonte, dada a sua condição de artefato capaz de combinar imagens, texto e materialidade, elementos significativos para estruturá-las, analisá-las e interpretá-las. O que torna as moedas únicas, no entanto, é sua natureza dupla, tanto de objeto arqueológico como de documento histórico. Ao prontamente responder algumas questões, o autor deixa claro que a Numismática é, ao mesmo tempo, uma disciplina autônoma, com teorias e métodos próprios, mas que raramente existe isolada como curso de graduação, mestrado ou doutorado. Na maior parte das vezes, ela aparece conjugada com a Arqueologia ou com a História. Isso não é mero acaso, pois, embora a interpretação das moedas não possa ser feita sem antes lidar com um conjunto de métodos e conceitos numismáticos, isso deve ocorrer dentro um quadro histórico ou arqueológico mais geral (WOLTERS; ZIEGERT, 2017, p. 7-8). Kemmers é enfático ao dizer que as moedas antigas não se desenvolveram nem existiram no vácuo, mas eram parte integrante das sociedades antigas. Mas, além disso, elas também não podem ser estudadas sem levar em conta as abordagens mais recentes da pesquisa histórica e arqueológica. Mediante a explanação preliminar, o objetivo de The functions and use of Roman coinage é enfatizado pelo autor: avaliar criticamente os estudos numismáticos e 
suas contribuições para a História Antiga em geral, com ênfase no mundo romano, da República até a Antiguidade Tardia.

O capítulo seguinte, "Methodological, theoretical, and technological developments", ainda na esteira propedêutica, foi construído com o objetivo de discutir os desenvolvimentos metodológicos, teóricos e tecnológicos da Numismática. Não é novidade que, nas últimas décadas, o campo numismático romano testemunhou alguns desenvolvimentos significativos ao se tratar de possibilidades tecnológicas, reflexões metodológicas e fundamentos teóricos. Estes últimos, por sua vez, influenciaram as perguntas feitas ao material numismático. Tais desenvolvimentos descritos pelo autor concentram-se na recorrente descoberta de moedas, na contribuição da Geoquímica e da Arqueometalurgia para as análises de metais de moedas antigas, nos conceitos derivados dos campos da Economia e da Antropologia, além, é claro, dos benefícios oriundos da difusão da World Wide Web, como a construção de bancos de dados online e a consolidação de uma comunidade de estudiosos sobre o tema.

Apesar dos desenvolvimentos teóricos, metodológicos e tecnológicos mencionados acima, as obras de referência e catálogos nos quais os vários tipos de moedas são organizados, descritos e datados foram e continuam sendo essenciais para os estudos numismáticos. E por essa razão, Kemmers (2019, p. 8-15) dedica o capítulo seguinte, "Structuring the material", a responder a seguinte pergunta: onde encontrar a visão mais atualizada dos tipos de moedas cunhadas no mundo romano? Sem dúvida, os trabalhos de referência mais utilizados na área são mencionados - mas não sem apontar seus ganhos e limitações - o que inclui os clássicos Roman Republican Coinage, Roman Imperial Coinage e Roman Provincial Coinage, além de novas bases de dados, como a Historia Numorum Italy, obras de apoio, como as de Robert Göbl (1978), Maria R.-Alföldi (1978), Andrew Burnett (1987), William E. Metcalf (2012) e Michel Amandry (2017), e até mesmo materiais de colecionadores. É importante lembrar, como bem afirma o autor, que diante das várias descobertas, todo corpus está sujeito a alterações.

No capítulo seguinte, "Coins as a means of communication", Kemmers (2019, p. 15-37) apresenta e discute uma das abordagens mais utilizadas pelos historiadores que empregam dados numismáticos em suas investigações: o potencial de comunicação das moedas. Entre as considerações do autor, podemos mencionar a defesa de que as moedas são o resultado de decisões tomadas por determinado órgão político, como o Senado, o imperador, um conselho municipal ou um magistrado, com motivos e mensagens específicas e implicações práticas dessas decisões, que incluem diversas etapas, como a produção, escolha de símbolos, quantidade e distribuição. Não podemos perder de vista que a cunhagem de moedas romanas configurava até mesmo um dos meios de 
o imperador e sua família mostrarem-se presentes nas províncias mais longínquas do Império, o que contribui, em grande medida, para consolidar e reforçar a autoridade dos soberanos representados nas efígies (SILVA, 2014, p. 66). A autopromoção se fazia cada vez mais necessária para as autoridades políticas (MANCINI, 2015, p. 94). Segundo Williams (2007, p. 157), o imperador era visto como o "autor público" da cunhagem de moedas em Roma e o regulador do sistema de produção dentro das oficinas de cunhagem. Desse modo, caberia ao soberano, com seus subordinados, escolher os elementos que estariam presentes nas moedas, a quantidade que tais moedas seriam cunhadas e sua finalidade extra econômica. O que a cunhagem mais obviamente oferecia era uma enorme gama de representações autodefinidas e explícitas que abrangiam o público, o oficial e as identidades (MILLAR, 2001). Anna Clark (2007, p. 139) classificou as moedas como pequenos "espaços portáteis", nos quais os moedeiros podiam pensar sobre si mesmos, suas famílias, sua cidade, sua trajetória e seu presente. Com tais características em mente, Kemmers busca diferenciar a cunhagem de moedas ao longo da história de Roma, dividindo-a em República, Principado, Antiguidade Tardia e Províncias. Chamamos atenção para a diferenciação entre a produção monetária ocorrida nas províncias daquela produzida em Roma, fator fundamental para analisar as várias cidades, regiões e períodos romanos. Kemmers, mediante o estudo de Howgego (2005, p. 2-16), afirma que os cultos locais, a evocação do passado mítico, a ênfase em épocas ou idiomas locais, a representação do ambiente natural ou construído da cidade eram maneiras de uma cidade se diferenciar das outras e enfatizar seu caráter único. ${ }^{1}$

Com a evidente discussão do papel das moedas na comunicação de mensagens imperiais e locais, o objetivo básico da cunhagem, ou seja, produzir instrumentos de valor monetário, é quase esquecido. Mas Kemmer (2019, p. 37-53), em seu capítulo "Coins as monetary instruments", faz questão de recordar as funções financeiras das moedas. Para isso, o autor apresenta os insights mais recentes sobre os parâmetros técnicos numismáticos, a saber: como e onde as moedas foram cunhadas; em que locais; peso e espessura; procedência do material de produção; quantidade cunhada; denominação e classificação. Além disso, o autor evoca a importância de compreendermos os aspectos dos pagamentos estatais, da política monetária e fiscal, seja da República, seja do Principado, seja da Antiguidade Tardia.

Já o último capítulo da obra resenhada, "Use of coinage", faz conexão direta com o título do livro, e evoca temas pertinentes ao cumprimento da propostas do autor, como

\footnotetext{
${ }^{1}$ Rowan (2016, p. 25-34) discutiu como as moedas locais e regionais, às vezes, empregavam imagens ambíguas, que podiam ser lidas como uma continuidade de suas próprias tradições ou como uma representação do poder romano, dependendo de quem manipulava esses artefatos.
} 
o imperialismo romano, a expansão territorial, as práticas monetárias e a circulação de moedas - tanto na zona rural como por intermédio do exército. O autor traça tais pontos e sugere implicações da cunhagem de moedas na integração da economia romana (2019, p. 54-62). Por fim, na conclusão de seu livro, Kemmers (2019, p. 63) retoma as considerações de Jones e afirma que este provavelmente estaria satisfeito com os bancos de dados robustos desenvolvidos por meio dos usos da internet e de novas tecnologias, já que tais bancos muito beneficiam os especialistas em História Antiga. É fato que os numismatas ainda fazem catálogos, recorda o autor, mas a disciplina é muito mais do que isso.

Em linhas gerais, The functions and use of Roman coinage: an overview of $21^{\text {st }}$ century scholarship é um passeio pela literatura numismática do século XXI, na qual as perguntas feitas por Kemmers são respondidas por insights e abordagens mais atuais. É de se reconhecer o esforço do autor em relacionar a historiografia sobre as moedas romanas com os aspectos básicos da pesquisa numismática, como conceitos e métodos. Kemmers demonstra domínio das obras mais recentes, sem deixar de retornar aos clássicos, que serviram e ainda servem de base para o estudo das moedas antigas. Apesar de curta, a obra em questão possui conteúdo confiável, atualizado e preciso, com destaque para a bibliografia selecionada.

Se tivermos que mencionar os problemas de The functions and use of Roman coinage, podemos apontar a falta de explicação de conceitos e termos específicos da área, bem como a ausência de introduções mais esclarecedoras aos assuntos abordados, o que dificulta a compreensão de leitores menos familiarizados com a temática abordada, uma vez que, como o próprio autor declara, o público-alvo do livro inclui estudantes. O número restrito de páginas poderia explicar a carência de uma explanação mais detalhada. Porém, esse não é o caso, visto que alguns assuntos são muito mais explorados que outros, o que causa um estranhamento na leitura, que ora apresenta-se repleta de detalhes e ora superficial, até mesmo apressada. Por último, sentimos falta de menções aos métodos de análise propriamente ditos, das moedas e de seus símbolos e, também, da relação monetária com a religião. ${ }^{2}$ Embora alguns exemplares de moedas romanas tenham sido apresentados, estes não foram analisados ou utilizados como exemplos para a compreensão das práticas numismáticas, apenas serviram como ilustrações do argumento.

\footnotetext{
${ }^{2}$ Gostaríamos de destacar que elementos religiosos são recorrentes nas moedas romanas, seja mediante a representação de deuses, de templos ou de práticas religiosas. De acordo com Howgego (2001), os romanos do Império continuaram com a tradição republicana de cunhar nas moedas expressões de suas mais diversas religiosidades, expressandoas como elementos de poder. Os imperadores também associavam sua imagem a deuses específicos, de modo a estabelecer uma conexão com atributos que a divindade escolhida exibia (MANCINI, 2015, p. 95).
} 
De uma forma ou de outra, The functions and use of Roman coinage: an overview of $21^{\text {st }}$ century scholarship é uma obra atualizada, com uma bibliografia recente e que contempla de maneira satisfatória os problemas e abordagens que envolvem a Numismática, a Arqueologia e a História Antiga, a exemplo das funções das moedas como veículos de comunicação política e instrumentos econômicos, a política monetária consciente por parte das autoridades e o impacto da expansão romana na monetização e no uso de moedas no Império Romano.

\section{Referências}

ALFÖLDI, M. R. Antike Numismatik. Mainz: Zabern, 1978.

AMANDRY, M. (ed.). La monnaie antique. Grèce et Rome: VIle siècle av. J.-C.-Ve siècle apr. J.-C. Paris: Ellipses, 2017.

BURNETT, A. Coinage in the Roman world. London: Seaby, 1987.

CLARK, A. J. Divine qualities: cult and community in Republican Rome. Oxford: Oxford University Press, 2007.

FRÈRE, H. Numismática: uma introdução aos métodos e à classificação. São Paulo: Sociedade Numismática Brasileira, 1984.

GÖBL, R. Antike numismatik. Munich: Battenberg, 1978.

HOWGEGO, C. AncieLLLLnt history from coins. London: Routledge, 2001.

HOWGEGO, C. Coinage and identity in the Roman Provinces. In: HOWGEGO, C.; HEUCHERT, V.; BURNETT, A. (Ed.). Coinage and identity in the Roman Provinces. Oxford: Oxford University Press. 2005, p. 1-17.

JONES, A. H. M. Numismatics and History. In: CARSON, R. A. G.; SUTHERLAND, C. H. V. (Ed.). Essays in Roman coinage: presented to Harold Mattingly. Oxford: Oxford University Press, 1956, p. 13-33.

KEMMERS, F. The functions and use of Roman coinage: an overview of $21^{\text {st }}$ century scholarship. Leiden: Brill, 2019.

MANCINI, W. Poder imperial e lugares de culto nas representações numismáticas do principado de Cláudio. Romanitas - Revista de Estudos Grecolatinos, n. 5, p. 93-111, 2015.

METCALF, W. E. (Ed.). The Oxford handbook of Greek and Roman coinage. Oxford: Oxford University Press, 2012.

MILLAR, F. The emperor in the Roman world. London: Duckworth, 2001.

ROWAN, C. Ambiguity, iconology and entangled objects on coinage of the Republican world. The Journal of Roman Studies, v. 106, p. 21-57, 2016. 
SILVA, C. F. P. A moeda como um discurso: uma análise das representações de Otávio, Cleópatra e Marco Antônio. De Rebus Antiquis, año 4, n. 4, p. 55-67, 2014.

WILLIAMS, J. Religion and roman coins. In: RÜPKE, J. (Ed.) A companion to Roman religion. Malden: Blackwell, 2007, p. 143-163.

WOLTERS, R.; ZIEGERT, M. (Org.). Numismatik lehren in Europa. Vienna: Österreichische Forschungsgesellschaft für Numismatik, 2017. 